\title{
Cobalt(II) and Nickel(II) Complex Compounds with the Acrylic Acid-Acrylamide Copolymer
}

\author{
A. S. Zaitsev, B. F. Levchenko, V. D. Buikliskii, and N. N. Bukov \\ Kuban State University. ul. Stavropol'skaya 149, Krasnodar, 350040 Russia \\ e-mail:s_work@inbox.ru
}

Received November 11, 2010

DOI: $10.1134 / \mathrm{S} 1070363211050203$

A possibility of using transition metal coordination compounds as intermediates in the synthesis of nanostructured composite materials with important practical (electrical, magnetic and optical) properties provokes a great interest to these compounds [1]. We synthesized and studied complexes of cobalt(II) and nickel(II) with the acrylic acid copolymer with acrylamide. The complex compounds of ions $\mathrm{Co}^{2+}$ and $\mathrm{Ni}^{2+}$ were prepared by dissolving a freshly prepared metal hydroxide in $0.5 \%$ solution of the ligand. The resulting complexes in the solid form are films of bright crimson and green color typical of the cobalt(II) and nickel(II) coordination compounds, respectively. Complexes are well soluble in water and sparingly soluble in organic solvents.

In the DTA curves of these complex compounds endothermic effects were observed in the vicinity of $70^{\circ} \mathrm{C}$ with a total $\sim 6 \%$ weight loss that corresponded to the removal of the absorbed water. The exothermic effect at the $420-456^{\circ} \mathrm{C}$ corresponded to the oxidation of the organic part of the complexes. The endothermic effects at the $470-503^{\circ} \mathrm{C}$ are associated with the destruction of the complex compounds.

The consideration of the data of thermal analysis and the results of atomic absorption studies leads to a conclusion that four ligand donor groups are attached to each metal ion. The complexes empirical formula is $\mathrm{ML}_{2} \cdot \mathrm{H}_{2} \mathrm{O}$, the coordinated water molecule is in the outer sphere. Changes in the infrared spectra of complex compounds in comparison with the IR spectrum of the ligand indicate bidentate binding of the oxygen atoms of carboxy group and monodentate binding of the oxygen atoms of carbamide group with the metal ion, while the amide nitrogen atom is not involved in the coordination. The electron absorption spectra of the cobalt complex indicate a $d \rightarrow d$ transition ${ }^{4} \mathrm{~T}_{1 \mathrm{~g}}(\mathrm{~F})-{ }^{4} \mathrm{~T}_{1 \mathrm{~g}}(\mathrm{P})$ at $19400 \mathrm{~cm}^{-1}$. In the nickel complex occur three transitions: $v_{1}={ }^{4} \mathrm{~T}_{1 \mathrm{~g}}(\mathrm{~F}) \rightarrow{ }^{4} \mathrm{~T}_{2 g}$; $v_{2}={ }^{4} \mathrm{~T}_{1 \mathrm{~g}}(\mathrm{~F}) \rightarrow{ }^{4} \mathrm{~A}_{2 g}$, and $v_{3}={ }^{4} \mathrm{~T}_{1 \mathrm{~g}}(\mathrm{~F}) \rightarrow{ }^{4} \mathrm{~T}^{\mathrm{lg}}(\mathrm{P})$, indicating six-coordinated pseudooctahedral environment [2].

We succeeded to obtain nanosized metal particles $(5-20 \mathrm{~nm})$ through reduction of the complex compounds with sodium borohydride followed by evaporation of the solutions. The formation of nanoscale metal particles inside the structure of the ligand was confirmed using scanning electron spectroscopy. The nanocomposites are stable in dry air, but decompose at the contact with moisture. The study of magnetic properties of polymer nanocomposites obtained showed that the nanoparticles possess "superparamagnetic" properties.

\section{REFERENCES}

1. Buikliskii, V.D., Sirota, A.V., Zaitsev, A.S., Bespalov, A.V., Pis'menskaya, N.D., Sista, F., and Koba, I.S., Nanotekhnika, 2008, no. 1 (13), p. 89.

2. Lever, A.B.P., Inorganic Electronic Spectroscopy, Moscow: Mir, 1987. 